| Dossiê: Impactos e Repercussões Socioambientais de Empreendimentos na Pan-Amazônia | DOI: http://dx.doi.org/10.18764/2446-6549.e202012

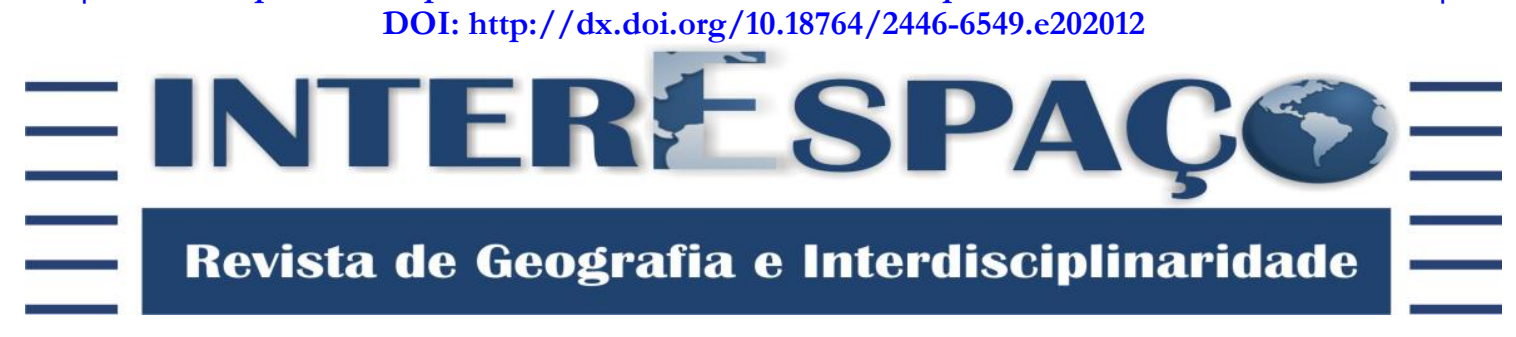

\title{
DISPUTAS NOS TERRITÓRIOS DA PESCA ARTESANAL BRASILEIRA COMO EXPRESSÃO DA DIALÓGICA ENTRE TERRITÓRIO E AMBIENTE
}

\author{
DISPUTES IN THE TERRITORIES OF BRAZILIAN ARTISANAL FISHING \\ AS AN EXPRESSION OF THE DIALOGIC BETWEEN TERRITORY AND \\ ENVIRONMENT
}

\section{DISPUTAS EN LOS TERRITORIOS DE LA PESCA ARTESANAL BRASILEÑA COMO UNA EXPRESIÓN DEL DIÁLOGO ENTRE TERRITORIO Y MEDIO AMBIENTE}

Cristiano Quaresma de Paula
Doutor e Mestre em Geografia pela Universidade Federal do Rio Grande do Sul - UFRGS. Pósdoutor em Geografia pela Universidade Federal do Pará - UFPA. Docente do Instituto de Ciências

Humanas e da Informação e do Programa de Pós-Graduação em Geografia da Universidade Federal do Rio Grande - PPGEO/FURG. cqpgeo@gmail.com / http://orcid.org/0000-0002-0220-909X

\section{Christian Nunes da Silva}

Doutor em Ecologia Aquática e Pesca pela Universidade Federal do Pará - UFPA. Professor do

Programa de Pós-Graduação em Geografia e do Programa de Pós-Graduação em Gestão de Recursos Naturais e Desenvolvimento Local na Amazônia - NUMA/UFPA.

cnsgeo@yahoo.com.br / http://orcid.org/0000-0002-8295-4910

Recebido para avaliação em 30/06/2020; Aceito para publicação em 21/09/2020.

\section{RESUMO}

As condições ambientais e a permanência de territórios tradicionais na pesca artesanal brasileira estão ameaçadas diante das disputas no território. A análise de 71 dissertações e teses, defendidas na Geografia Brasileira entre 1982 e 2015, permitiu distinguir a presença de impactos ambientais, conflitos por território e disputas no território, como expressão da dialógica entre território e ambiente. Quanto às disputas no território, destacadas neste artigo, estão relacionadas principalmente à aquicultura, pesca industrial, pesca comercial e geração de energia. Deve-se ressaltar que a espacialização de dissertações e teses demonstra a concentração dessas disputas em contextos intrarregionais no Brasil. As disputas no (e pelo) território correlacionam os impactos ambientais e os conflitos territoriais, o que levou ao colapso dos estoques pesqueiros e à desterritorialização dos pescadores artesanais brasileiros.

Palavras-chave: Pesca Artesanal; Território; Ambiente; Geografia.

\begin{abstract}
The environmental conditions and the permanence of traditional territories in Brazilian artisanal fishing are threatened in the face of disputes in the territory. The analysis of 71 dissertations and theses, defended in the Brazilian Geography between 1982 and 2015, allowed distinguishing the presence of environmental impacts, conflicts by territory and disputes in the territory, as an expression of the dialogic between territory and environment. As for the disputes in the territory, highlighted in this article, are mainly related to aquaculture, industrial fishing, commercial fishing
\end{abstract}


|Disputas nos territórios da pesca artesanal brasileira como expressão da dialógica entre território e ambiente |

|Cristiano Quaresma de Paula | Christian Nunes da Silva |

and power generation. It should be emphasized that the spatialization of dissertations and theses demonstrates the concentration of these disputes in intra-regional contexts in Brazil. Disputes in (and by) territory correlate environmental impacts and territorial conflicts, which has led to the collapse of fish stocks and deterritorialization of Brazilian artisanal fishermen.

Keywords: Artisanal Fishing; Territory; Environment; Geography.

\section{RESUMEN}

Las condiciones ambientales y la permanencia de los territorios tradicionales en la pesca artesanal brasileña se ven amenazadas ante las disputas en el territorio. El análisis de 71 disertaciones y tesis, defendidas en la Geografía brasileña entre 1982 y 2015, permitió distinguir la presencia de impactos ambientales, conflictos por territorio y disputas en el territorio, como expresión de la diálogo entre territorio y ambiente. En cuanto a las disputas en el territorio, destacadas en este artículo, están relacionadas principalmente con la acuicultura, la pesca industrial, la pesca comercial y la generación de energía. Cabe destacar que la espacialización de disertaciones y tesis demuestra la concentración de estas disputas en contextos intrarregionales en Brasil. Las disputas en (y por) territorio correlacionan los impactos ambientales y los conflictos territoriales, lo que ha llevado al colapso de las poblaciones de peces y la desterritorialización de los pescadores artesanales brasileños.

Palabras clave: Pesca Artesanal; Territorio; Ambiente; Geografía.

\section{INTRODUÇÃO}

O presente artigo destaca a relação entre os conceitos de território e ambiente em dissertações e teses, defendidas por geógrafos, sobre a pesca artesanal. Apresentou-se em De Paula (2018a) essa dialógica a partir de três abordagens: impactos ambientais, disputas no território e conflitos por território. Neste artigo, será destacada a abordagem de disputas no território.

Impactos ambientais são causados por outras atividades econômicas e resultam na extinção de territórios tradicionais de pesca. Nesta perspectiva está acentuado o conceito de ambiente como condição para a perenidade do território. Os conflitos por território ocorrem quando outras atividades econômicas buscam o domínio do território apropriado pelas comunidades de pescadores artesanais. Nesse caso, destaca-se o conceito de território como espaço de exercício do poder. Já as disputas no território, evidenciam relações de apropriação com o objetivo de acessar os recursos ambientais, evidenciando os conceitos de território e ambiente (DE PAULA, 2018a, 2019).

Dos 71 trabalhos analisados (61 dissertações e 10 teses defendidas por geógrafos entre 1982 e $2015^{1}$ ), 14,71\% tratam de impactos ambientais, cujas principais causas são industrialização, urbanização, agricultura e pesca industrial (DE PAULA, 2019), 51,47\% enaltecem conflitos por território, promovidos principalmente por questões fundiárias,

\footnotetext{
${ }^{1}$ Disponíveis na Biblioteca Digital Brasileira de Teses e Dissertações (BDTD) e nos sites dos Programas de Pós-Graduação em Geografia.
} 
|Disputas nos territórios da pesca artesanal brasileira como expressão da dialógica entre território e ambiente |

|Cristiano Quaresma de Paula | Christian Nunes da Silva |

turismo, especulação imobiliária e unidades de conservação e 38,87\% destacam disputas no território, decorrentes prioritariamente da aquicultura, pesca industrial, pesca comercial, geração de energia.

As disputas no território expõem a relação entre território e ambiente, na medida em que a presença de recursos ambientais gera disputas entre pescadores e com outras atividades econômicas, que por consequência tendem a comprometer a continuidade de tais recursos em condições de sustentabilidade. Destarte as disputas no território expõem tanto impactos ambientais quanto conflitos por território. Acrescenta-se que, além das disputas por recursos, entram em choque visões de natureza e lógicas de apropriação (RAFFESTIN, 1996; SUERTEGARAY, 2009), o que impede a perenidade dos recursos ambientais no território.

Para compreender as disputas no território na pesca artesanal brasileira, em um primeiro momento serão apresentados estágios que resultam em tais disputas, e assim na Territorialização-Desterritorialização-Reterritorialização (TDR) dos pescadores artesanais. $\mathrm{Na}$ sequência serão apresentadas as principais atividades que promovem tais disputas no território com as comunidades tradicionais de pescadores artesanais.

\section{A ECOGÊNESE TERRITORIAL E A CONSTITUIÇÃO DE DISPUTAS NO TERRITÓRIO}

Raffestin (1986a) propõe a compreensão da ecogênese territorial, na qual a delimitação, a centralização e a comunicação são o cerne do processo de TerritorializaçãoDesterritorialização-Reterritorialização (TDR). A análise das invariantes territoriais (nós, redes e malhas) é fundamental para compreender a dinâmica de criação e regulamentação das "reservas" (podem ser lidos como recursos ambientais), pelas comunidades tradicionais de pescadores (RAFFESTIN, 1986b).

Com base na compreensão de "quadros de natureza" de Moscovici (1968) serão apresentados os processos de TDR da pesca artesanal em três estágios, propostos por De Paula (2018a). Esses estágios não devem ser compreendidos isolados, mas a partir dos processos.

Parte-se de um estágio em que o território não se expressa delimitado. Os pescadores artesanais utilizam os recursos do ambiente, por meio do saber ambiental (LEFF, 2010) que incita o manejo, mas sem concorrências. Nesse estágio da ecogênese territorial, corresponde a primazia das relações com a natureza, de acordo com seus ciclos, o que Suertegaray (2017) chama de "território da natureza". As territorialidades se 
| Disputas nos territórios da pesca artesanal brasileira como expressão da dialógica entre território e ambiente |

| Cristiano Quaresma de Paula | Christian Nunes da Silva |

manifestam nos conhecimentos sobre o espaço para o acesso aos recursos, correlancionando condições ambientais, com artes de pesca (técnicas e apetrechos). A apropriação se manifesta, então, no saber, o qual é compartilhado na comunidade.

Neste estágio o território tradicional não constitui uma malha delimitada, mas uma rede, muito influenciada pela dinâmica da natureza (sobretudo onde está o peixe), que ligam os nós das áreas de pesca com os das áreas de moradia, de forma fluída. A proximidade entre área de moradia e de pesca define tais territorialidades, pois as condições de navegação são reduzidas.

No segundo estágio, devido às condições naturais ou de uso, os recursos ambientais estão menos acessíveis, o que resulta em uma busca maior por recursos ambientais, de forma que o saber da sua localização e das técnicas de obtenção constitui-se em poder. No âmbito comunitário esse poder não significa domínio, logo o saber (compartilhado) integra acordos verbais de uso. Esse poder é resultado de um processo de comunicação bemsucedida, a partir de objetivos comuns (RAFFESTIN; BARAMPAMA, 1998, p. 64). Logo, as informações funcionais e regulatórias se combinam (RAFFESTIN, 1996) e há soberania da comunidade, pois o tempo da produção se mantém em compasso com o tempo do consumo (TAPIA, 2008).

O terceiro estágio apresenta o contexto em que, devido à redução dos recursos pesqueiros e/ou a pressão pelo aumento da produção, os saberes que harmonizavam o uso comum são convertidos em estratégias de apropriação e domínio (emergência da pesca comercial e industrial). São estabelecidas disputas por recursos (inclusive dos corpos d'água no caso da aquicultura, hidrelétricas, portos etc.), as quais podem resultar em impactos ambientais e conflitos por território no âmbito da comunidade, intercomunitário, e com usuários exógenos.

Evidencia-se o que Suertegaray (2017) entende como "a natureza do território", pois as relações de poder se impõem sobre os saberes e relações sociais. Nas comunidades as tensões resultam do desrespeito às regras estabelecidas, demonstrando fissuras e erosão do conhecimento tradicional. Nesse contexto, comunidades passam a reivindicar o direito de uso exclusivo do território, estabelecendo limites, bem como estratégias de manutenção desses limites, o que provoca cisões entre comunidades, dificultando a articulação entre as mesmas a partir de objetivos comuns.

As disputas intensas pelos nós (no caso dos pesqueiros), faz com que os mais piscosos sejam raros. Da mesma forma o saber sobre sua localização constitui um poder, o qual nem sempre é partilhado, mesmo no âmbito comunitário. Há contextos em que são 
|Disputas nos territórios da pesca artesanal brasileira como expressão da dialógica entre território e ambiente |

| Cristiano Quaresma de Paula | Christian Nunes da Silva |

estabelecidas estratégias para dificultar o acesso a esses nós (principalmente para pescadores exógenos).

$\mathrm{Na}$ pesca artesanal brasileira coexistem essas fases dependendo das condições ambientais dos corpos d'água, da presença de recursos pesqueiros, do número de pescadores, da coesão social, e da apresentação de outras atividades do "setor pesqueiro" como pesca industrial, comercial e amadora, ou que fazem uso dos corpos d'água como aquicultura, hidrelétricas e portos.

No estágio atual há tentativa das comunidades de pescadores de retorno ao segundo estágio apresentado, contudo para além das tensões territoriais existentes na pesca acrescenta-se a influência dos territórios das instituições e, principalmente, o avanço de outras atividades econômicas sobre o território tradicional.

Diante do exposto, é importante destacar aqui a compreensão de territorialidades da pesca artesanal adotada:

As territorialidades da pesca artesanal são evidentes no âmbito das comunidades e integram áreas de pesca e de recursos que são utilizados nas pescarias. Logo, abrangem pesqueiros, matas, manguezais, ranchos de pesca, locais de beneficiamento, etc. O poder se expressa no saber, que é compartilhado entre os comunitários por meio de conhecimentos tradicionais, que suscita práticas de uso. A informação inerente a esse saber é funcional e regulatória, logo ocorre o manejo, por meio de acordos que são elaborados na pesca e no cotidiano. Essas territorialidades são fluidas, conectadas por trajetos, canais, varadouros. Mudam de acordo com a dinâmica da natureza e movimento dos cardumes. No arranjo territorial as áreas terrestres, de trabalho, moradias e vivência também compõem territorialidades, e ocupam o papel de centralidade. Nesta ocorre a comunicação, e se evidencia a gestão comunitária (DE PAULA, 2018a, p. 373).

Ressalta-se que essas territorialidades podem se sobrepor (de diferentes comunidades) sem incidir em conflitos, quando é estabelecido um processo de comunicação (funcional e regulatória) com base na troca de conhecimentos, e no respeito a certas normas, formais e informais. Nesse contexto é importante compreender o território comunitário:

O território comunitário é substantivado pelas territorialidades tradicionais, terra e água, área da comunidade e pesqueiros. E se caracteriza pelo estabelecimento de relações simétricas de poder (prestígio). A sustentação desse território se dá por meio de um processo comunicacional, que mobiliza todos os atores, que dependem em certo grau dos recursos locais (da reserva), para a manutenção dos mesmos. Assim, a partir da coesão social se estabelecem acordos, normas, processos de monitoramento e sansões construídos no âmbito comunitário e intercomunitário, em processos democráticos participativos (informação funcional e regulatória). Assim, o território expressa as relações comunitárias e com a natureza, sendo fundamental na reprodução social, cultural e econômica das comunidades (DE PAULA, 2018a, p. 374). 
|Disputas nos territórios da pesca artesanal brasileira como expressão da dialógica entre território e ambiente |

| Cristiano Quaresma de Paula | Christian Nunes da Silva |

Entretanto, esse território comunitário vem se adaptando à realidade atual, devido, principalmente, às novas dinâmicas causadas pelo aumento na intensidade do consumo do pescado, criando espaços profícuos para a pesca predatória ou a criação de peixes em cativeiros, que representam os principais desafios na gestão dos recursos pesqueiros no Brasil.

\section{DISPUTAS NO TERRITÓRIO NA PESCA ARTESANAL BRASILEIRA}

As disputas no território se dão pelo domínio (do sítio), assim como pelos recursos do ambiente. Por consequência, essas disputas causam tanto impactos quanto conflitos, que influenciam a dinâmica territorial da pesca artesanal.

Nesse momento serão destacadas as disputas entre pesca artesanal e outras atividades econômicas. Essas atividades estão relacionadas em redes técnicas e informacionais muitas vezes de outras escalas de comando (regional, nacional e global). A pressão das redes e a conjunção de uma perspectiva de fomento da economia leva os gestores públicos a privilegiar e flexibilizar a entrada desses empreendimentos no território.

As disputas no território se evidenciaram 69 vezes nas dissertações e teses analisadas. A região Nordeste apresenta a maior parte dessas disputas mapeadas (46,38\%). A região Norte concentra $(18,84 \%)$ e a região Sul $(14,29 \%)$. A região Sudeste totaliza $(13,30 \%)$ e a região Centro-Oeste $(1,45 \%)$ dos trabalhos analisados, como apresenta o mapa (Figura 1). 
| Disputas nos territórios da pesca artesanal brasileira como expressão da dialógica entre território e ambiente |

|Cristiano Quaresma de Paula | Christian Nunes da Silva |

Figura 1 - Mapa de Disputas no Território, por Região

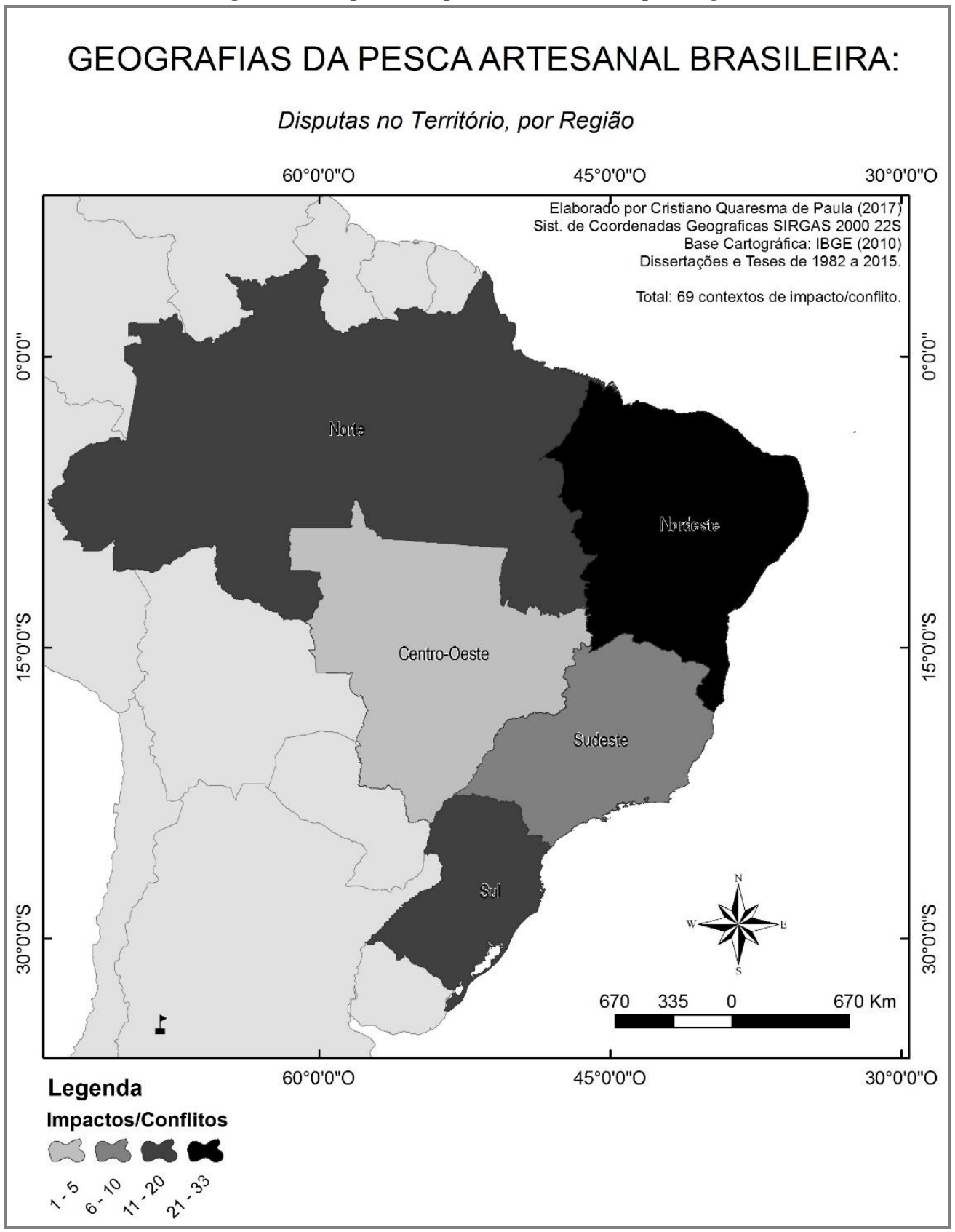

Fonte: Elaborado por De Paula (2018a)

Destaca-se que estas disputas no território identificadas nas dissertações e teses são concentradas dentro das regiões. A Figura 2 destaca essa densidade na região Norte, na costa paraense e no Amazonas, afluentes do rio Solimões; na região Nordeste, ao longo da costa brasileira, principalmente nos estuários, como o do rio São Francisco; na região Sul, os casos identificados são prioritariamente localizados no estuário da Laguna dos Patos, Lago Guaíba e região litorânea; e na região Sudeste, no Litoral do Rio de Janeiro e de São Paulo. 
| Disputas nos territórios da pesca artesanal brasileira como expressão da dialógica entre território e ambiente |

|Cristiano Quaresma de Paula | Christian Nunes da Silva |

Figura 2-Mapa de Densidade de Disputas no Território, no Brasil

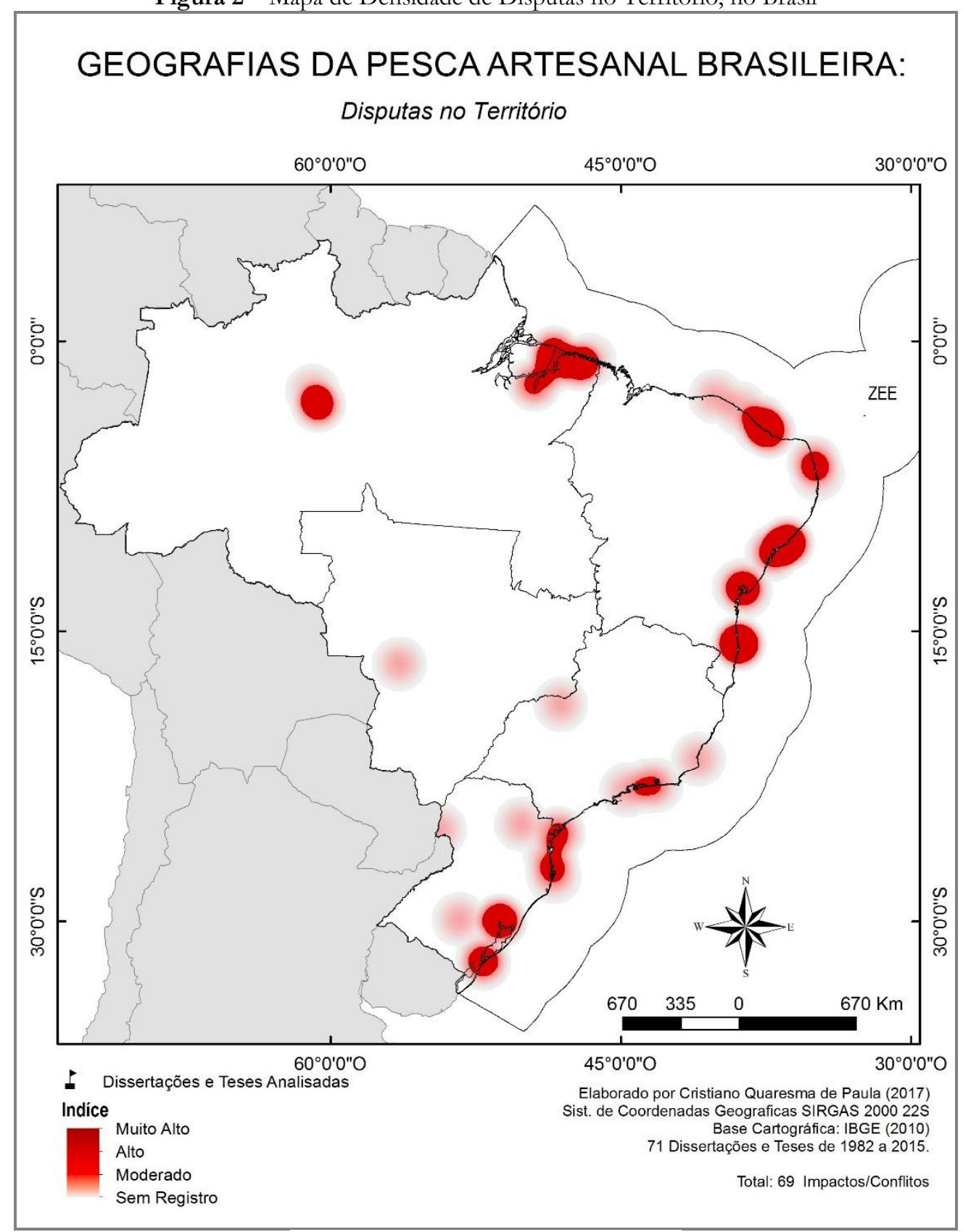

Fonte: Elaborado por De Paula (2018a).

De Paula (2018a) destaca que há diversidade de atividades que concorrem por territórios e recursos com a pesca artesanal. As principais disputas observadas são as relacionadas à aquicultura, pesca industrial, pesca comercial e geração de energia.

$\mathrm{Na}$ análise das dissertações e teses, a aquicultura configura-se como a atividade econômica que provoca disputas no território. As modificações no ambiente causadas por essa atividade influem na quantidade e qualidade do pescado. Devido à perda de produtividade na pesca, os pescadores artesanais são desterritorializados. Acrescenta-se que quando é instalada sobre o território pesqueiro, impede o acesso dos pescadores e 
|Disputas nos territórios da pesca artesanal brasileira como expressão da dialógica entre território e ambiente |

\section{| Cristiano Quaresma de Paula | Christian Nunes da Silva |}

interrompe o manejo comunitário. O Estado frequentemente fomenta essa atividade econômica sem reconhecer os territórios comunitários dos pescadores artesanais.

No Nordeste brasileiro, Santos (2008, p. 73) expõe problemas ambientais relacionados à carcinicultura. Em Acaraú (Ceará) houve a "descaracterização de áreas, inundações, diminuição na quantidade e variedade de peixes e camarões de pesca, destruição dos mangues, salinização do lençol freático e poluição das margens dos rios”. Segundo a autora, o território pesqueiro se extingue e os filhos de pescadores não se reproduzem socialmente na pesca.

Rodrigues (2005, p. 14) expõe o "desmatamento das áreas de mangue visando à construção de tanques, canais para captação de água do rio e a descarga de dejetos dos viveiros” em Aracati (Ceará). Tais mudanças afetam o equilíbrio do ecossistema dos manguezais, levando à desterritorialização de pescadores artesanais e das marisqueiras.

No Rio Grande do Norte, em Canguaretama, Galvão Neto (2009) apresenta a supressão de manguezais devido à indiscriminada instalação de empresas de aquicultura, sobretudo, a carcinicultura no mangue. Também frisa a restrição ao "acesso de pescadores a seus sítios tradicionais de pesca e de abrigo e manutenção de suas embarcações, através da construção de cercas e da ação de vigias armados” (GALVÃO NETO, 2009, p. 46).

No Estuário do rio São Francisco (Alagoas e Sergipe), Cunha (2006) identificou em trabalhos de campo a implantação de viveiros para a carcinicultura, os quais "tem representado um fator decisivo para os problemas de ordem ambiental, econômica e social, pois a vegetação de mangue é retirada" (p.124). Os governos incentivam o cultivo de camarão no Baixo São Francisco em vez de priorizarem o "fortalecimento da pesca artesanal e da coleta de crustáceos e moluscos na mesma área, bem como os valores socioculturais da população local" (p.122). Os "proprietários" dos viveiros restringem o acesso por parte dos pescadores e catadores de caranguejo com "cercas, caracterizando a apropriação de um espaço que anteriormente era de uso coletivo” (p. 200). Como consequência dessas mudanças, Cunha (2006, p. 104) destaca a "perda da identidade cultural e dos saberes da tradição, sendo necessário traçar metas de planejamento econômico-ambiental que consistam em propor direções para a dinâmica sociocultural dos moradores".

Em Nossa Senhora do Socorro (Sergipe), Santos (2012) aponta que para a promoção da carcinicultura houve o desmatamento do manguezal, comprometendo o pescado. Em decorrência da redução das áreas de mariscagem, os pescadores passaram a se deslocar para lugares mais distantes ou abandonaram essa atividade tradicional. 
| Disputas nos territórios da pesca artesanal brasileira como expressão da dialógica entre território e ambiente |

|Cristiano Quaresma de Paula | Christian Nunes da Silva |

Rios (2012) em Santo Amaro (Bahia) compreende que a primeira transformação decorrente da carcinicultura foi a retirada do mangue para dar lugar aos viveiros de cultivo do camarão. Logo, "a inserção de empreendimentos relacionados à carcinicultura no território da pesca artesanal constitui-se em formas de apropriação/produção diferenciadas em um espaço de uso comum” (RIOS, 2012, p. 65). Isto tem colocado a comunidade em constante alerta quanto à transformação das condições sociais, ambientais, culturais e econômicas de seu território.

Na compreensão de Kuhn (2009), o território pesqueiro apresenta danos causados pela carcinicultura, como a destruição das áreas de mangue, e pela concorrência do mercado. Em São Francisco do Paraguaçu - Bahia houve a redução das possibilidades de negociação do pescador artesanal, que não tem como concorrer com os investimentos e com a escala da produção da carcinicultura.

Figueiredo (2013) ressalta que em Canavieiras (Bahia), os tanques criatórios são instalados sobre o mangue, resultando em poluição por dejetos, modificações no sistema natural hídrico e a supressão da vegetação. Neste município Machado (2007, p. 83-84) enfatiza transformações nas áreas de manguezais próximas das fazendas de camarão, como consequências da "construção de tanques sobre a produtividade estuarina com a substituição dos manguezais, e a queda da produtividade dos bancos de corais devido à morte dos organismos". Figueiredo (2013) e Dumith (2012) enfatizam o papel do Estado no fomento a esses projetos e flexibilização de licenciamentos ambientais.

$\mathrm{Na}$ região Sul, Custódio (2006) frisa os impactos da maricultura em Governador Celso Ramos (Santa Catarina). Para o autor, "superpopulações em algumas áreas de produção podem trazer problemas de poluição das águas, devido ao acúmulo de dejetos, distúrbios das comunidades naturais de fitoplâncton e contaminação dos estoques" (CUSTÓDIO, 2006, p. 77). Essas mudanças nos pesqueiros afetam diretamente as espécies pesqueiras, o que compromete a permanência da pesca artesanal.

A pesca industrial avança sobre os territórios tradicionais da pesca artesanal e compromete o equilíbrio dos estoques pesqueiros. Essa forma de apropriação dos recursos que não reconhece o tempo da natureza e seus ciclos, foi a principal responsável pelo colapso dos recursos pesqueiros no Brasil. Muitas vezes, a pesca industrial busca recursos específicos, mas os apetrechos de pesca são pouco seletivos, capturando o pescado que seria objeto da pesca artesanal no adequado estágio de maturação.

$\mathrm{Na}$ região Nordeste, Lima (2002) informa que a pesca industrial de Lagosta "miúda" interrompe o ciclo reprodutivo desta espécie. A degradação dos estoques pesqueiros resulta na redução da rentabilidade dos pescadores artesanais, os quais 
|Disputas nos territórios da pesca artesanal brasileira como expressão da dialógica entre território e ambiente |

| Cristiano Quaresma de Paula | Christian Nunes da Silva |

dependem dos recursos presentes no território. O embate entre pesca industrial e artesanal tem provocado "guerras no mar" "crônicas, de uma tragédia anunciada pelo descaso do poder público, pela falta de fiscalização e pela ganância dos empresários do setor pesqueiro" (LIMA, 2002, p. 206).

No Norte do Brasil também se evidencia a distinção entre os objetivos e interesses da pesca artesanal e industrial em torno do uso dos territórios, como aponta Guedes (2009). A intensificação da pressão sobre os recursos tem resultado na redução da quantidade do peixe. Nas localidades Céu e Cajuúna, no Marajó, há uma disputa latente entre pescadores artesanais e pescadores industriais no litoral paraense.

Lima (2008) destaca o avanço da pesca industrial predatória sobre o estuário amazônico, levando os pescadores artesanais a buscarem pesqueiros em locais mais distantes. Por isso, há um incremento no esforço de pesca e se evidenciam conflitos entre pescadores que migram e os pescadores locais. "Dessa forma, as questões econômicas, técnicas e ambientais se intercruzam e a mobilidade é cada vez mais forçada para garantir a sobrevivência do pescador" (LIMA, 2008, p. 58-59).

No Sudeste, são distintas as técnicas utilizadas por pescadores artesanais e industriais, como aponta Giannella (2009, p. 120). "Esses barcos de pesca industriais localizam os cardumes através de aparelhos sofisticados, como o GPS e sonar, e capturam tudo o que o pescador artesanal levaria meses para pescar em apenas um dia”.

No litoral Norte paulista, Cardoso (1996, p. 70) evidencia a presença de grandes barcos atuaneios e caçoeiros, bem como os barcos de arrasto de camarão, que "são apontados pelos pequenos pescadores como responsáveis pela diminuição do pescado na região". Os pescadores artesanais observam a redução dos principais estoques pesqueiros, e entram em disputa com os pescadores industriais (do arrasto e do cerco).

Na região Sul, na Vila de Superagui, Guaraqueçaba (Paraná), Pérez (2012) apresenta o enfrentamento entre pescadores artesanais e pescadores industriais. Ao contrário dos dados estatísticos, que não indicam uma significativa presença da pesca industrial no estado, os pescadores expõem que "há efetivamente presença industrial, que vem especialmente de Santa Catarina, estado que tem um dos maiores índices de presença da pesca industrial" (PEREZ, 2012, p. 45).

Em Barra Velha, Santa Catarina, o Estado intervém estabelecendo limites para a pesca industrial e artesanal, como aponta Machado (2013). O estabelecimento de uma área exclusiva para a pesca artesanal acabou reduzindo os conflitos por território. Contudo, a pesca industrial intensificou a atuação no entorno, reduzindo o pescado disponível para o 
| Disputas nos territórios da pesca artesanal brasileira como expressão da dialógica entre território e ambiente |

| Cristiano Quaresma de Paula | Christian Nunes da Silva |

pescador artesanal, que detém pouca infraestrutura para a navegação e acaba tendo que realizar pescarias em áreas protegidas.

As dissertações e teses também apresentam disputas no território com a pesca comercial. Neste caso, a pressão sobre os recursos pesqueiros tem reduzido os estoques, o que resulta na maior competição entre pescadores artesanais e comerciais pelos pesqueiros mais piscosos.

Na região Norte, Silva (2009) expõe a complexidade dos diversos interesses dos profissionais embarcados e camponeses-ribeirinhos que se lançaram na pesca comercial por um lado, e camponeses-ribeirinhos que não concordavam com a invasão dos seus territórios pesqueiros de outro. É emblemático o caso ocorrido no Lago Januacá, no estado do Amazonas, em 1973, com mortes de ribeirinhos e pescadores comerciais, evento conhecido na região como "guerra do peixe".

Na leitura de Lima (2008), a "guerra do peixe" não foi só uma competição por recursos, mas a manifestação de resistência de um modelo social de reprodução. Foi um problema a ser resolvido por toda uma coletividade local e de outras localidades das proximidades. No dia do ocorrido, um barco saiu para buscar, nas margens do rio, os "soldados" para essa guerra, ainda na madrugada. O clima de tensão se espalhou pelas proximidades, os homens saíam armados com faca, terçado, machado, espingardas com munição e outros meios para a defesa de seu território de pesca, ameaçado por membros externos (ABREU, 2011, p. 74).

Em Manacapuru (Amazonas), polo regional de venda de pescado, Abreu (2011) evidencia que o aumento da procura por pescado no rio Solimões tem resultado na redução dos estoques e disputas entre pescadores "de fora" e os das comunidades locais. "A existência de conflitos se deu no início da delimitação da área para a pesca (o lanço) e sua apropriação pelos comunitários" [...] “essa situação se agravou bastante, sendo necessária a intervenção de instituições do judiciário" (ABREU, 2011, p. 69-70).

No baixo rio Solimões, Cruz (2007) aponta que a redução dos recursos pesqueiros alertou as comunidades quanto ao uso do ambiente em condições acima da sua capacidade de resiliência, levando a proposições em defesa dos seus territórios tradicionais. Encontros promovidos em Itacoatiara (1985), Coari (1986) ficaram conhecidos como "do movimento em defesa da escassez do peixe no estado do Amazonas". No $3^{\circ}$ Encontro, por exemplo, em 1986, o irmão Falco Michelis, apresentou a proposta da prelazia de Tefé, de preservação dos lagos a partir de um zoneamento (CRUZ, 2007, p. 181).

Araújo (2012), em Augusto Corrêa (Pará), analisa as disputas entre pescadores locais e pescadores comerciais imigrantes do Ceará, que fazem uso de técnicas predatórias. 
| Disputas nos territórios da pesca artesanal brasileira como expressão da dialógica entre território e ambiente |

| Cristiano Quaresma de Paula | Christian Nunes da Silva |

O autor destaca o papel dos empresários e donos de embarcação nordestinos nesses processos de disputas no território entre pescadores migrantes e os pescadores tradicionais locais.

No Nordeste, o diálogo com as lideranças comunitárias de Canavieiras (Bahia) permitiu a Machado (2007) compreender que os problemas mais sérios são os de ordem estrutural, ou seja, a pesca comercial predatória, inclusive a praticada por pescadores de outros estados, os quais avançam sobre os territórios tradicionais das comunidades locais.

Os empreendimentos de geração de energia hidrelétrica também promovem disputas no território com a pesca artesanal. Esses projetos avançam sobre pesqueiros tradicionais e territórios ocupados pelas comunidades. Os pesqueiros são afetados por mudanças nas características hidrológicas dos rios, o que compromete todo o habitat das espécies capturadas pela pesca artesanal. Essas comunidades quando desterritorializadas, perdem suas residências, sua organização social, assim como memórias (individuais e coletivas).

No Norte do Brasil, no município de Cametá (Pará), Cruz (2006) identifica uma drástica redução na produtividade da pesca, devido às alterações no regime hidrológico do rio após a construção da barragem da Hidroelétrica de Tucuruí. Nesses contextos, entendese que "ritmo de enchente e vazante passou a ser regulado pelas atividades de operação da UHE" (CRUZ, 2006, p. 120). As consequências se evidenciam na desorientação e modificação do comportamento migratório dos cardumes de espécies de peixes comerciais da região. Além do impacto ecológico há impactos sociais e culturais no baixo Tocantins, já que o rio tem papel fundamental na construção do modo de viver dos ribeirinhos (CRUZ, 2006, 2011). A construção da hidrelétrica provocou a desterritorialização das comunidades ribeirinhas, indígenas e urbanas, pois sofreram mobilização compulsória, sendo obrigadas a deixar suas casas, terras, pesqueiros, etc. (CRUZ, 2011).

$\mathrm{Na}$ região Nordeste, no estuário do rio São Francisco (Alagoas e Sergipe), as barragens foram construídas ao longo do rio, resultando em alterações na dinâmica do sistema fluvial, as quais interferem na organização socioeconômica da população residente (CUNHA, 2006). No caso da Usina Hidrelétrica de Xingó, Cunha (2011, p. 206) destaca que "a baixa vazão maximiza problemas como a extrema redução da carga de sedimentos, com consequências na cadeia alimentar, interferindo na transferência de energia e nutrientes entre produtores e consumidores".

No Sudeste, bacia do rio Araguari, no triângulo mineiro, Braconaro (2011) aponta que a biodiversidade ictiológica é prejudicada com a construção das usinas hidrelétricas, resultando na redução ou extinção da pesca para grande parte da população rural. A pesca 
|Disputas nos territórios da pesca artesanal brasileira como expressão da dialógica entre território e ambiente |

| Cristiano Quaresma de Paula | Christian Nunes da Silva |

foi extinta, em decorrência do represamento, onde a maioria dos peixes que existiam não se reproduzem nessas novas condições. Além das perdas materiais, subtraem-se referências socioespaciais que foram herdadas, construídas individualmente e coletivamente e que, historicamente, garantiam meios de vida e produção com a exploração das terras, das águas e das matas (BRACONARO, 2011, p. 108).

Na região Sul, Ferreira (2014) compreende que a instalação e funcionamento da Usina Hidrelétrica Itaipu Binacional (Paraná) provocou modificações nas territorialidades dos pescadores artesanais. O fechamento das comportas da Usina de Itaipu, ou a escassez de chuvas, rebaixa o nível do lago, o que na época da desova (ou piracema, entre os meses novembro a fevereiro) provoca redução nos estoques pesqueiros. Além da perda de territórios com a instalação da usina, os pesqueiros tradicionais são abandonados por não haver produtividade.

Além dos contextos apontados, a análise das dissertações e teses permitiu reconhecer, embora em número menos expressivo, a presença de outras atividades promotoras de disputas no território como: indústria, turismo, agricultura, comercialização de pescado, indústria do petróleo, abordagens de fiscalização, mineração, pesca amadora, portos, ausência de fiscalização, e criação de unidades de conservação (DE PAULA, 2018a).

\section{CONSIDERAÇÕES FINAIS}

Importa destacar que as disputas no território, embora apresentadas de forma distinta nesse artigo, envolvem tanto impactos ambientais, quanto conflitos por território, como é defendido por De Paula (2018a).

Essas disputas foram visíveis na região Nordeste, onde a aquicultura (principalmente a carcinicultura) é identificada como principal atividade causadora. Além dos impactos provenientes do uso de produtos químicos é fundamental destacar os conflitos relacionados às restrições dos acessos dos pescadores artesanais aos pesqueiros tradicionais. Nesta região há grande pluralidade de outras atividades que causam impactos e conflitos por território, como a comercialização de pescado, usinas hidrelétricas, pesca industrial, indústria do petróleo e a atividade do turismo.

$\mathrm{Na}$ região Sul, a principal atividade apontada como promotora de disputas no território é a pesca industrial. Ocorrem conflitos entre pescadores artesanais e pescadores industriais, muitas vezes de outros estados. Entende-se que os pescadores industriais possuem capacidade de captura muito superior a dos pescadores artesanais e, dispondo de 
|Disputas nos territórios da pesca artesanal brasileira como expressão da dialógica entre território e ambiente |

| Cristiano Quaresma de Paula | Christian Nunes da Silva |

maiores condições de mobilidade, não se preocupam como a perenidade dos recursos presentes no território. A resistência à pesca industrial tem sido promovida em espaços de discussão e gestão da pesca, como os Fóruns de Pesca, e com a construção de normativas que favorecem os pescadores locais.

Na região Norte, as disputas no território são destacadas prioritariamente na pesca comercial, pela submissão aos desígnios do capital, contrariando a lógica tradicional, resultando na sobre-exploração dos pesqueiros que tradicionalmente são utilizados pelos pescadores artesanais. Entram em conflito pescadores comerciais e pescadores artesanais pelos recursos presentes no território.

Também se evidenciam conflitos entre pesca industrial e pesca artesanal na região Norte. Além da pressão da cadeia de comercialização, as relações de produção distinguem pescadores artesanais (proprietários dos meios de produção) de pescadores industriais (empregados dos proprietários dos barcos). Soma-se o choque entre a lógica de produção artesanal (no tempo da natureza) e a lógica industrial (no tempo da máquina), que resulta em impactos ambientais.

Também no Norte do Brasil, a geração de energia hidrelétrica é apontada como causa de disputas no território. A descaracterização dos corpos d'água leva a extinção de territórios pesqueiros tradicionais. Ocorre também a remoção das comunidades de seus territórios tradicionais para a construção de barragens.

$\mathrm{Na}$ região Sudeste, a pesca industrial é identificada como principal atividade que disputa recursos no território com a pesca artesanal. Seus impactos ambientais têm resultado no colapso dos recursos pesqueiros, bem como em conflitos com os pescadores artesanais.

A geração de energia elétrica, assim como industrialização naval e portos dizem respeito ao uso dos corpos d'água para instalação de outras atividades econômicas, que prometem o desenvolvimento e a modernização. No entanto, além dos prejuízos irreparáveis que causam ao ambiente e aos recursos pesqueiros, retiram os pescadores artesanais de seus territórios tradicionais de moradia e restringem o acesso aos pesqueiros.

Frente às disputas no território, os pescadores artesanais brasileiros resistem. Um dos meios de resistência tem sido a constituição de um território de luta, ou seja, a adoção do argumento da permanência no território tradicional, como fundamento para o acesso às políticas públicas voltadas para os povos e comunidades tradicionais (DE PAULA, 2018a).

\section{REFERÊNCIAS}


|Disputas nos territórios da pesca artesanal brasileira como expressão da dialógica entre território e ambiente |

|Cristiano Quaresma de Paula | Christian Nunes da Silva |

ABREU, Georgete Cabral de. Território da pesca: o uso do espaço aquático no baixo rio Solimões município de Manacapuru-AM. 2011. 106 f. Dissertação (Mestrado em Geografia) - Programa de Pós-Graduação em Geografia, Universidade Federal do Amazonas, Manaus, 2011.

ARAÚJO, Glauco Rivelino Ferreira de. Migração, territorialização e pesca em Augusto Correa - PA (1990-2010). 2012. 158 f. Dissertação (Mestrado em Geografia) - Programa de Pós-Graduação em Geografia, Universidade Federal do Pará, Belém, 2012.

BRACONARO, Fernando. A geografia da pesca: modo de vida e lazer na bacia do Rio Araguari-MG. 2011. 204 f. Dissertação (Mestrado em Geografia) - Programa de PósGraduação em Geografia, Universidade Federal de Uberlândia, Uberlândia, 2011.

CARDOSO, Eduardo Schiavone. Vitoreiros e monteiros: ilhéus do Litoral Norte Paulista. 1996. Dissertação (Mestrado em Geografia) - Programa de Pós-Graduação em Geografia Humana, Universidade de São Paulo, São Paulo, 1996.

CRUZ, Manoel de Jesus Masulo da. Territorialização camponesa na várzea amazônica. 2007. Tese (Doutorado em Geografia) - Programa de Pós-Graduação em Geografia Humana, Universidade de São Paulo, São Paulo, 2007.

CRUZ, Valter Carmo. Lutas sociais, reconfigurações identitárias e estratégias de reapropriação social do território na Amazônia. 2011. 368 f. Tese (Doutorado em Geografia) - Programa de Pós-Graduação em Geografia, Universidade Federal Fluminense, Niterói, 2011.

CRUZ, Valter Carmo. Pela outra margem da fronteira: território, identidade e lutas sociais na Amazônia. 2006. 201 f. Dissertação (Mestrado em Geografia) - Programa de Pós-Graduação em Geografia, Universidade Federal Fluminense, Niterói, 2006.

CUNHA, Alessandra Sampaio. Fragmento de território de pesca na Amazônia: Comunidade Segredinho/Capanema-PA. 2011. 141 f. Dissertação (Mestrado em Gestão dos Recursos Naturais e Desenvolvimento Local na Amazônia) - Programa de PósGraduação em Gestão dos Recursos Naturais e Desenvolvimento Local na Amazônia, Universidade Federal do Pará, Belém, 2011.

CUNHA, Cleidinilson de Jesus. Regularização da vazão e sustentabilidade de agroecossistemas no estuário do rio São Francisco. 2006. 232 f. Dissertação (Mestrado em Geografia) - Programa de Pós-Graduação em Geografia, Universidade Estadual da Ceará, Fortaleza, 2006.

CUSTÓDIO, Jonas Simas. Caminhos da produção familiar artesanal em Governador Celso Ramos/SC: da Pesca Maricultura. 2006. 155 f. Dissertação (Mestrado em Geografia) - Programa de Pós-Graduação em Geografia, Universidade Federal de Santa Catarina, Florianópolis, 2006.

DE PAULA, Cristiano Quaresma. Geografia(s) da Pesca Artesanal Brasileira. 2018. 451 f. Tese (Doutorado em Geografia) - Programa de Pós-Graduação em Geografia, Universidade Federal do Rio Grande do Sul, Porto Alegre, 2018a.

DE PAULA, Cristiano Quaresma. Impactos ambientais na pesca artesanal brasileira: uma interpretação geográfica. PerCursos, v. 19, n. 41, p. 79-106, 2019. 
|Disputas nos territórios da pesca artesanal brasileira como expressão da dialógica entre território e ambiente |

|Cristiano Quaresma de Paula | Christian Nunes da Silva |

DUMITH, Raquel Carvalho. Dinâmicas do sistema de gestão na reserva extrativista de Canavieiras (BA): análise da robustez institucional e de possibilidades para o ecodesenvolvimento. 2012. Dissertação (Mestrado em Geografia) - Programa de PósGraduação em Geografia, Universidade Federal do Rio Grande, Rio Grande, 2012.

FERREIRA, Graziele. Comunidade de pescadores artesanais no Lago Itaipu conflitos territoriais na Colônia Z11 de São Miguel do Iguaçu/PR. 2014. 207 f. Dissertação (Mestrado em Geografia) - Programa de Pós-Graduação em Geografia, Universidade Estadual do Oeste do Paraná, Francisco Beltrão, 2014.

FIGUEIREDO, Marina Morenna Alves de. Trabalho e participação político-social das pescadoras na RESEX Canavieiras - BA. 2013. 116 f. Dissertação (Mestrado em Geografia) - Programa de Pós-Graduação em Geografia, Universidade Federal da Bahia, Salvador, 2013.

GALVÃO NETO, João. O território das novas economias e suas implicações socioambientais na comunidade pesqueira de Barra do Cunhaú. 2009. $140 \mathrm{f}$. Dissertação (Mestrado em Geografia) - Programa de Pós-Graduação em Geografia, Universidade Federal do Rio Grande do Norte, 2009.

GIANNELLA, Letícia de Carvalho. Entre o mar e a metrópole: desenvolvimento, território e identidade da comunidade de pescadores de Copacabana, Rio de Janeiro/RJ. 2009. Dissertação (Mestrado em Geografia) - Programa de Pós-Graduação em Geografia, Pontifícia Universidade Católica do Rio de Janeiro, Rio de Janeiro, 2009.

GUEDES, Eneias Barbosa. Território e territorialidade de pescadores nas localidades Céu e Cajuuna Soure-Pa. 2009. 161 f. Dissertação (Mestrado em Geografia) - Programa de Pós-Graduação em Geografia, Universidade Federal do Pará, Belém, 2009.

KUHN, Ednizia Ribeiro Araújo. Terra e água: Territórios dos pescadores artesanais de São Francisco do Paraguaçu-Bahia. 2009. 173 f. Dissertação (Mestrado em Geografia) Programa de Pós-Graduação em Geografia, Universidade Federal da Bahia, Salvador, 2009.

LEFF, Enrique. Epistemologia ambiental. Tradução de Sandra Valenzuela. São Paulo: Cortez, 2010.

LIMA, Maria do Céu. Comunidades pesqueiras marítimas no Ceará território, costumes e conflitos. 2002. 220 f. Tese (Doutorado em Geografia) - Programa de PósGraduação em Geografia, Universidade de São Paulo, São Paulo, 2002.

LIMA, Marta. Mobilidade geográfica como estratégia de sobrevivência de pescadores artesanais na Amazônia: o caso de Cubatão em Icoaraci, Pará. 2008. 120 f. Dissertação (Mestrado em Geografia) - Programa de Pós-Graduação em Geografia, Universidade Federal do Pará, Belém, 2008.

MACHADO, Cristina Buratto Gross. O território da pesca artesanal da Colônia Z4, Barra Velha, SC: o paradoxo entre a tradição e a modernidade. 2013. 117 f. Dissertação (Mestrado em Geografia) - Programa de Pós-Graduação em Geografia, Universidade Estadual do Centro-Oeste, Guarapuava, 2013.

MACHADO, Ricardo Augusto Souza. O meio natural na organização produtiva da população pesqueira tradicional do município de Canavieiras. 2007. 159 f. 
|Disputas nos territórios da pesca artesanal brasileira como expressão da dialógica entre território e ambiente |

|Cristiano Quaresma de Paula | Christian Nunes da Silva |

Dissertação (Mestrado em Geografia) - Programa de Pós-Graduação em Geografia, Universidade Federal da Bahia, Salvador, 2007.

PÉREZ, Mercedes Solá. Comunidade tradicional de pescadores e pescadoras artesanais da vila do Superagüi-PR na disputa pela vida: conflitos e resistências territoriais frente à implantação de políticas públicas de desenvolvimento. 2012. $150 \mathrm{f}$. Dissertação (Mestrado em Geografia) - Programa de Pós-Graduação em Geografia, Universidade Federal do Paraná, Curitiba, 2012.

RAFFESTIN, Claude ; BARAMPAMA, Angelo. Espace et pouvoir. In: BAILLY, Antoine. Les concepts de la géographie humaine. Paris: Armand Colin, 1998. p. 63-71.

RAFFESTIN, Claude. De la nature aux images de la nature. Espaces et Sociétés, n. 8283, p. 37-52, 1996.

RAFFESTIN, Claude. Ecogenèse territoriale et territorialité. In: AURIAC, F. ; BRUNET, R. Espaces, jeux et enjeux. Paris: Fayard \& Fondation Diderot, 1986a. p. 175-185.

RAFFESTIN, Claude. Punti di riferimento per una teoria della territorialita' umana. In: COPETA, Clara. Esistere e abitare. Prospettive umanistiche nella Geografia francofona. Milano: Franco Ageli, 1986b. p. 75-89.

RIOS, Kássia Aguiar Norberto. Da produção do espaço a construção dos territórios pesqueiros: pescadores artesanais e carcinicultores no Distrito de Acupe - Santo Amaro (BA). 2012. 262 f. Dissertação (Mestrado em Geografia) - Programa de PósGraduação em Geografia, Universidade Federal da Bahia, Salvador, 2012.

RODRIGUES, Francisco Gleison de Souza. O agronegócio da carcinicultura marinha e os conflitos sociais e ambientais de uso e ocupação do estuário do rio Jaguaribe no município de Aracati-CE. 2005. 122 f. Dissertação (Mestrado em Geografia) Programa de Pós-Graduação em Geografia, Universidade Federal do Ceará, Fortaleza, 2005.

SANTOS, Eline Almeida. (Re)produção social e dinâmica ambiental no espaço da pesca reconstruindo a territorialidade das marisqueiras em Taiçosa de Fora-Nossa Senhora do Socorro/SE. 2012. 163 f. Dissertação (Mestrado em Geografia) -Programa de Pós-Graduação em Geografia da Universidade Federal do Sergipe, São Cristóvão, 2012.

SANTOS, Maria Auxiliadora Ferreira dos. Análise do processo de internalização de propostas de educação ambiental em escolas de Ensino Médio no município de Acaraú-CE. 2008. 111 f. Dissertação (Mestrado em Geografia) - Programa de PósGraduação e Pesquisa em Geografia, Universidade Federal do Rio Grande do Norte, Natal, 2008.

SILVA, Crisanto Damião da. Pesca: classes sociais, territorialidades e trabalho em Manacapuru-AM. 2009. 145 f. Dissertação (Mestrado em Geografia) - Programa de PósGraduação em Geografia, Universidade Federal do Amazonas, Manaus, 2009.

SUERTEGARAY, Dirce Maria Antunes. Religar a geografia: natureza e sociedade. Porto Alegre: Compasso Lugar-Cultura, 2017. 179 p. 
| Disputas nos territórios da pesca artesanal brasileira como expressão da dialógica entre território e ambiente |

|Cristiano Quaresma de Paula | Christian Nunes da Silva |

SUERTEGARAY, Dirce Maria Antunes. Pesquisa de Campo e Geografia. GEOgraphia, Niterói, 2009.

TAPIA, Luis Mealla. Política salvaje. Consejo Latinoamericano de Ciencias Sociales CLACSO: La Paz, 2008. 122 p.

\section{Como citar este artigo:}

\section{ABNT}

DE PAULA, C. Q.; SILVA, C. N. Disputas nos territórios da pesca artesanal brasileira como expressão da dialógica entre território e ambiente. InterEspaço: Revista de Geografia e Interdisciplinaridade, v. 6, e202012, 2020. Disponível em: <http://dx.doi.org/10.18764/2446-6549.e202012>. Acesso em: 25 jan. 2020.

\section{APA:}

De Paula, C. Q.; \& Silva, C. N. (2020). Disputas nos territórios da pesca artesanal brasileira como expressão da dialógica entre território e ambiente. InterEspaço: Revista de Geografia e Interdisciplinaridade, v. 6, e202012. Recuperado em 25 janeiro, 2020, de http://dx.doi.org/10.18764/2446-6549.e202012

\section{C.creative}

This is an open access article under the CC BY Creative Commons 4.0 license.

Copyright (C) 2020, Universidade Federal do Maranhão.

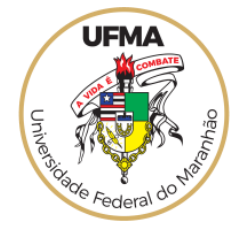

